REVISTA DE GEOCIÊNCIAS DO NORDESTE

Northeast Geosciences Journal

v. $6, \mathrm{n}^{\circ} 1(2020)$

ISSN: 2447-3359

https://doi.org/10.21680/2447-3359.2020v6n1ID18768

\title{
ATIVIDADES EXPERIMENTAIS COMO PRÁTICA DE ENSINO- APRENDIZAGEM DE TEMAS DE GEOGRAFIA FÍSICA NO ENSINO MÉDIO
}

\section{Clelfa Monteiro Pereira ${ }^{1}$; Isorlanda Caracristi ${ }^{2}$}

${ }^{1}$ Mestre em Geografia, Centro de Ciências Humanas, Universidade Estadual Vale do Acaraú (UVA), Sobral/CE, Brasil. ORCID: https://orcid.org/0000-0003-2842-8861

Email: clelfamonteiro@hotmail.com

${ }^{2}$ Doutora em Geografia, Centro de Ciências Humanas, Universidade Estadual Vale do Acaraú (UVA), Sobral/CE, Brasil. ORCID: https://orcid.org/0000-0002-3777-7417

Email: icaracristi@hotmail.com

\section{Resumo}

Vários estudos que se referem à Geografia Física apontam as dificuldades para a abstração e compreensão por parte dos alunos dos ensinos fundamental e médio, como os conceitos na área de climatologia e hidrografia, apresentados neste trabalho. A produção de materiais didáticos específicos e a aplicação de técnicas interativas podem contribuir para melhorar o processo de aprendizagem do discente e nessa perspectiva as atividades experimentais são exemplos de recursos didáticos acessíveis e de fácil desenvolvimento em sala que auxiliam o ensinoaprendizagem escolar para os temas da Geografia Física presentes no currículo do Ensino Médio. As atividades experimentais podem e devem se tornar práticas pedagógicas mais presentes nas estratégicas de ensino-aprendizagem, visto o salto no desenvolvimento cognitivo do aluno que elas proporcionam e suas possibilidades de aplicação em sala. Além de seu papel pedagógico, os experimentos também se transformam em momentos em que se desenvolve a interação e a socialização, e potencializa a criatividade dos alunos.

Palavras-chave: Ensino de Geografia Física; Práticas Experimentais; Aquecimento Global.

EXPERIMENTAL ACTIVITIES AS A PRACTICE OF TEACHING-LEARNING OF THEMES OF PHYSICAL GEOGRAPHY IN MIDDLE SCHOOL

\begin{abstract}
Several studies referring to Physical Geography point out the difficulties for the abstraction and comprehension by the students of the elementary and high school, as the concepts in the area of climatology and hydrography, presented in this work. The production of specific didactic materials and the application of interactive techniques can contribute to improve the student's learning process and, in this perspective, the experimental activities are examples of accessible and easily developed classroom resources that help the teaching-learning of the subjects. of Physical Geography present in the High School curriculum. Experimental activities can and should become more present pedagogical practices in teaching-learning strategies, given the leap in the student's cognitive development that they provide and their possibilities for classroom application. In addition to their pedagogical role, experiments also become moments in which interaction and socialization develops, and enhances students' creativity .
\end{abstract}

Keywords: Physical Geography Teaching; Experimental Practices; Global Warming.

ACTIVIDADES EXPERIMENTALES COMO PRÁCTICA DE ENSEÑNANZA Y APRENDIZAJE PARA TEMAS DE GEOGRAFÍA FÍSICA EM LA ESCUELA SECUNDARIA

\section{Resumen}

Varios estudios que se refieren a la Geografía Física señalan las dificultades para la abstracción y la comprensión de los estudiantes de primaria y secundaria, como los conceptos en el área de climatología e hidrografía, presentados en este trabajo. La producción de materiales didácticos específicos y la aplicación de técnicas interactivas pueden contribuir a mejorar el proceso de aprendizaje del alumno y, en esta perspectiva, las actividades experimentales son ejemplos de recursos didácticos accesibles y de fácil desarrollo en el aula que ayudan a la enseñanzaaprendizaje escolar de los temas. de Geografía Física presente en el currículo de secundaria. Las actividades experimentales pueden 
y deben convertirse en prácticas pedagógicas más presentes en las estrategias de enseñanza-aprendizaje, dado el salto en el desarrollo cognitivo del alumno que proporcionan y sus posibilidades de aplicación en el aula. Además de su papel pedagógico, los experimentos también se transforman en momentos en los que se desarrollan la interacción y la socialización, y mejoran la creatividad de los estudiantes.

Palabras-clave: Enseñanza de Geografia Física; Prácticas Expetimentales; Calentamiento Global.

\section{INTRODUÇÃO}

A Geografia, área do conhecimento humano que vem da mais remota antiguidade, pode ser analisada através de seus estudos geográficos datados desde as primeiras civilizações. E, sob a influência de duas grandes escolas, foi principiada como ciência autônoma por volta do século XIX - com o Positivismo - e ao longo do século XX - com o advento do Marxismo.

Após esse período de transformações têm-se a fase da denominada Geografia Tradicional acadêmica e escolar dividida entre Física e Humana - que propunha a memorização principalmente dos aspectos da Geografia Física. Em âmbito nacional, por volta dos anos 70 e 80 , a perspectiva tradicional cede seu lugar à Geografia Crítica. Esta buscava o estudo crítico das relações sociais e socioespaciais, e com isso, acabava conferindo a si, um aspecto de ciência social.

Após esse período a Geografia Física passa por um processo de intensa especialização em subáreas, tornando seu avanço cientifico comandado por pesquisadores e estudantes cada vez mais especializados e autônomos, bem como seus eventos acadêmico-científicos, deixando à margem as questões voltadas ao ensino de geografia.

Por conseguinte, nos encontros como o "Fala Professor" promovidos pela Associação dos Geógrafos Brasileiros (AGB), como afirma AFONSO e ARMOND (2009) muitos pesquisadores falavam sobre as provocações de ensinar a Geografia Física. Estes eram principalmente sobre as dificuldades de abstração dos conteúdos, pelo desconhecimento da produção científica recente e de novos paradigmas metodológicos ou pelo desafio em perceber a relevância dos elementos ambientais para a vida cotidiana.

Assim, com os estudos históricos da evolução da ciência geográfica é possível perceber que desde sua concepção, a Geografia Física sofre com as dificuldades provindas dos ranços positivistas de produção do conhecimento, seja no processo de pesquisa como de ensino e extensão. Essa dificuldade se amplia principalmente em sua relação aplicativa cotidiana, seja na esfera da aplicação técnica ou escolar.

Tendo em vista estas colocações, o presente trabalho voltouse a analisar e elaborar proposição no âmbito do ensino da Geografia Física na Educação Básica no que compete aos conceitos de Bacia Hidrográfica e Aquecimento Global e com isso, questionamos a função da Geografia de outrora que se limitava apenas a descrever os fenômenos geográficos espaciais, com pouca tentativa de tornar técnicas e metodologias escolares mais interpretativas e participativas, onde o educando pudesse aprender se integrando na construção do conhecimento, conforme orientam os Parâmetros Curriculares Nacionais de Geografia, 1998, p. 135):

Entretanto, é possível trabalhar com esse campo do conhecimento de forma mais dinâmica e instigante para os alunos, por meio de situações que problematizem os diferentes espaços geográficos materializados em paisagens, lugares, regiões e territórios; que disparem relações entre o presente e o passado, o específico e o geral, as ações individuais e as coletivas; e que promovam o domínio de procedimentos que permitam aos alunos "ler" e explicar as paisagens e os lugares.

Isso reforça a necessidade da aplicação de um caráter, essencialmente prático e experimental, que deve permear a metodologia geográfica de hoje baseada nas experiências discentes e práticas pedagógicas construtivistas desenvolvidas em sala de aula.

Em consequência, a ação de ensinar Geografia tornou-se um grande desafio, desde que sua função ultrapassou a tarefa de apenas descrever os lugares e levar "estímulo ao amor à pátria através da exaltação da natureza" (CAMPOS, 1997). A criticidade, a pertinência cotidiana e a interatividade tornaram os processos de ensino-aprendizagem mais complexos, mas, em contrapartida, as legitimaram pelo retorno qualitativo do conhecimento construído e aprendido e pela repercussão positiva e permanente na formação cognitiva do educando.

A importância da Geografia é inegável quanto ao seu papel do ensino em geral neste século que versa sobre a busca de novas formas de melhorar a realidade. Desse modo, essa ciência compreende uma área de conhecimento comprometida em tornar o mundo compreensível para os alunos, explicável e passível de transformações (BRASIL, 1998, p. 26).

Nesse contexto metodológico e de intensões pedagógicas, as aplicações de técnicas experimentais são fundamentais e podem ser utilizadas como recursos para a evolução cognitiva e social do discente, uma vez que essas práticas conduzem o aluno a vivenciar a relação entre os conteúdos escolares conceituais e "abstratos" e a sua ap licação e materialização no ato construtivo da experiência empírica, por exemplo.

As atividades experimentais são alternativas acessíveis aos professores da rede básica de ensino para facilitar o estudo das temáticas ambientais, tais como Aquecimento Global e Bacias Hidrográficas. Além disso, podem se associar ao contexto da Educação Ambiental, que segundo afirma DIAS:

É considerada como um processo permanente no qual os indivíduos e a sociedade tomam consciência da condição do seu ambiente e adquirem os conhecimentos, os valores, as habilidades, as experiências e a determinação que os tornem aptos a agir individual e coletivamente e resolver problemas ambientais presentes e futuros. (1994, p.148).

E, levando em conta a crescente negligência com a natureza e os recursos naturais, impulsionada pelo sistema capitalista, o reforço de processos de formação de novos cidadãos com mais senso crítico e sensibilidade com as necessidades ambientais do 
planeta só contribuirá para a melhoria das discussões e atitudes acerca do meio ambiente no qual vivemos.

$\mathrm{O}$ uso de práticas experimentais acontece por meio de processos de ensino-aprendizagem, instigando o senso crítico e reflexivo do aluno, e por isso geram como será visto nos capítulos seguintes, uma melhor consolidação dos conhecimentos tão importantes para o seu cotidiano pessoal e coletivo.

\section{AS ATIVIDADES EXPERIMENTAIS NO ENSINO DE GEOGRAFIA FÍSICA}

\subsection{A importância das atividades experimentais na aprendizagem}

No Brasil, até a década de 80 o uso de experiências práticas, na rede básica de educação, teve como exemplo e incentivo às atividades experimentais que eram desenvolvidas nas universidades. Estas tinham como objetivo estimular a formação de novos cientistas, colaborando com a ampliação do quadro de profissionais produtores de conhecimento científico, até então, bastante reduzido (GALIAZZI, 2001, p. 253).

Já nos dias atuais, as aulas práticas, utilizando experimentos, vêm sendo desenvolvidas (mesmo que timidamente) para complementar e ajudar na compreensão das aulas teóricas e visando facilitar, a aprendizagem dos conteúdos da Geografia Física. Isso ocorre, uma vez que, as aulas práticas passam a contribuir para o desenvolvimento de habilidades essenciais no processo de formação do pensamento crítico e científico. Desse modo, inicia-se a fuga do modelo tradicional de ensino em que os alunos são apenas meros receptores e excluídos do processo de construção de seus conhecimentos e que estão sempre esperando uma resposta pronta para seus questionamentos.

Da mesma forma, a qualidade no processo ensinoaprendizagem encontra-se, atualmente, como tema bastante debatido na área da educação. E, levando em conta as constantes mudanças - sociais, econômicas, políticas e culturais - faz-se necessário considerar não só a coletividade, mas também o indivíduo e suas habilidades pessoais, conforme definido por Agnes Heller quando afirma que:

O homem torna-se indivíduo na medida em que produz uma síntese em seu EU, em que transforma conscientemente os objetivos e as aspirações sociais em objetivos e aspirações particulares de si mesmo e em que, desse modo, socializa "sua particularidade". (HELLER, 1982, p. 80).

É exigido do sistema educativo, em geral, certa qualidade no aprendizado dos discentes tendo em vista a formação de um cidadão competente e capaz de responder aos desafios colocados pela sociedade em que vivemos. E, para que isso aconteça, com qualidade, é necessário tratar o educando como um parceiro fundamental no desenvolvimento educativo. Além, obviamente, de entender a turma como uma comunidade que compartilha experiências e saberes.

Portanto, a partir daí, será possível se desenvolver metodologias pedagógicas que favoreçam a reflexão e construção dos conteúdos abordados em sala, propiciando ao aluno autonomia reflexiva, técnica e prática, que irá refletir na qualidade do processo ensino-aprendizagem e na formação desses jovens para o mundo do trabalho e para a vida.

Desta forma, as aulas práticas de ensino têm as funções, para o aluno, de despertar e dar continuidade no interesse dos conteúdos da disciplina de Geografia Física além de desenvolver as habilidades de solucionar questionamentos e compreender conceitos básicos Lunetta (1991, p. 203). Além disso, essas técnicas e metodologias são essenciais para o exame nacional do ensino médio (ENEM) que tem o papel de avaliar e auxiliar o ingresso dos discentes no ensino superior (fator objetivo, obviamente, dos alunos do ensino médio). Uma vez que, a matriz de referência de 2009 do referido exame (sendo as edições seguintes baseadas nesta) destaca a necessidade do desenvolvimento no Ensino Médio a compreensão de fenômenos, a solução de situações-problema, a elaboração de argumentos e o desenvolvimento de propostas para as mais variadas dificuldades encontradas na sociedade atual.

Neste contexto, as atividades experimentais aparecem como um exemplo de processos didáticos que enriquecem $\mathrm{e}$ diversificam as metodologias como ressalta Gómez:

(...) se justifica quando facilita para cada indivíduo um rico processo de aprendizagem e desenvolvimento sem limites conhecidos. Concretizar estes limites e especificálos em manifestações particulares observáveis é sucumbir de novo à intenção de controlar, matando a riqueza e cerceando a diversidade. $(1997$, p. 30).

Porém as Práticas Pedagógicas que se fazem tão necessárias como alternativas para que haja a visualização dos conceitos trabalhados na escola são em muitos casos negligenciadas, proporcionando assim as aulas, na maioria das vezes, baseadas na "transmissão passiva de informações aos alunos, pela ausência da relação com o quotidiano do educando e pelo predomínio de metodologias pouco criativas". (CARVALHO, 2009, p.12)

Assim, ensino e aprendizagem são processos inextricáveis, mas geram resultados diferentes nos sujeitos. Uma vez que cada aluno desenvolve seu próprio conhecimento, além de o fazer de modo idiossincrático (único), já que esse processo depende essencialmente do que o discente já conhece e vivenciou, ou seja, de seus conhecimentos anteriores, sendo este a base para a construção de novas ideias. Deste modo o resultado desse processo de aprendizagem é também diferente para cada estudante (FREIRE, 1987).

AUSUBEL (1978) ainda complementa, quando expõe que existem dois extremos quando o assunto é aprendizagem. De um lado a aprendizagem mecânica (conhecida no país, por muitos alunos e professores, como "decoreba") em que o estudante tem o papel de memorizar conceitos e fórmulas desconexos e desprovido de grandes significados para a sua vivencia. Por outro lado, tem-se a aprendizagem significativa, que compreende o advento de novos conhecimentos com a interligação de antigos (conceitos, fórmulas e vivencias até então empíricas) que já estão fixados na cognição do aluno de maneira substancial e nada arbitrária.

Igualmente, para que os estudantes possam ter disposição para apreender de modo significativo - interligar e inter-relacionar conceitos -, o mesmo deve estar inserido no contexto dos conceitos que a disciplina aborda em sala, para que desse modo 
os conhecimentos apreendidos em sala possam ser vivenciados no cotidiano dos discentes. Além, obviamente, da importância desta aula para a construção do seu futuro. Do contrário, o discente será levado a deduzir que é mais conveniente memorizar conceitos e fórmulas para esta ou aquela prova, para esquecê-los em seguida.

Portanto, ensino e aprendizagem são dois conceitos que se interligam profundamente e fazer com que estes passem a representar a construção e execução de uma mesma aula é sempre foi o objetivo primordial da Didática (CARVALHO, 2006).

E, entre os professores, esse pressuposto de que o docente precisa deixar o papel de ser apenas um repassador de informações para assumir um papel de mediador do conhecimento aos seus alunos, está ganhando bastante abertura e adeptos.

De tal modo, a temática ensino-aprendizagem é entendida por BORDENAVE (2001) como sendo necessária quando se passa a utilizar um método pedagógico que possibilite utilizar elementos multissensoriais mais recomendados para cada etapa do processo de desenvolvimento cognitivo do aluno. Neste sentido, o ensino, deixa de lado o seu papel de algo meramente informativo e abstrato e passa a agir também na formação de habilidades e competências.

Portanto, os educadores devem, na medida do possível, possibilitar ao discente um processo motivador de aprendizagem. E com isso nasce a debatida reflexão sobre como alcançar este objetivo de contribuir no desenvolvimento de ideias críticas e habilidades técnicas no estudante, principalmente, quando tange à necessidade de entender e intervir em sua realidade.

Nesse sentido, aulas práticas podem auxiliar neste processo de inter-relação e desenvolvimento de conceitos, além de proporcionar aos alunos o modo de como aproximar-se objetivamente de seu mundo, e como desenvolver recursos para problemas complexos encontrados ao longo de sua vida (LUNETTA, 1991).

KRASILCHIK (2008) afirma que dentre os vários métodos didáticos existentes, tais como aulas expositivas, demonstrações, excursões, discussões, aulas práticas e projetos, como forma de vivenciar o método científico, as aulas práticas e projetos são os mais apropriados. Ela ainda complementa que as funções das aulas práticas abrangem o despertar e a manutenção dos interesses dos alunos nas mesmas. Além, de envolvê-los nas investigações científicas, desenvolvimento da capacidade de resolver problemas e compreender conceitos básicos.

Nessas aulas práticas, os discentes têm a propriedade de interagir com as montagens de instrumentos específicos que normalmente eles não têm quando em contato com um ambiente com um caráter mais informal do que o ambiente da sala de aula (BORGES, 2002).

As aulas práticas são também uma boa forma de se examinar e auxiliar neste processo de ensino-aprendizagem dos alunos, como dito anteriormente, já que ao acompanhar este processo, o professor, tem a oportunidade de observar os progressos e as dificuldades de sua sala de aula. Sendo assim, uma atividade importante que o docente deve fazer para intermediar a solução das dificuldades que alguns alunos encontram em compreender o porquê e para quê estudar os conteúdos visto na escola (BIZZO, 2000).

Deste modo, o professor de Geografia deveria sempre ter como objetivo a vinculação da teoria com a prática em suas aulas.
E com o reconhecimento, por parte dos alunos, de sua importância (prática pedagógica), atesta-se que é essencial a disseminação dessa metodologia nas escolas.

Porém, como afirma KRASILCHIK (2008), as práticas pedagógicas são pouco difundidas, seja pela falta de tempo em desenvolver o material para a aula, como a insegurança ao controlar os alunos. Mas que, apesar de tudo, são perceptíveis o entusiasmo e o envolvimento dos nestas aulas práticas.

Portanto, a atividade experimental, na sala de aula, com a (re)utilização de materiais que objetivam dinamizar os conteúdos e os métodos de desenvolvimento do conhecimento de Geografia, faz-se essencial para o aluno (e professor).

\subsection{A experimentação no processo ensino-aprendizagem dos conteúdos de Geografia Física}

Durante muitos anos a Geografia conviveu com a dicotomia Geografia Física - Geografia Humana que acabava e acaba refletindo nos professores da disciplina no Ensino Médio que pautando suas aulas em um ensino descritivo e fragmentado, exige dos alunos habilidades de memorização sem tem um cuidado com a "explicação da inter-relação entre os processos, fossem eles de ordem natural ou social" (SUERTEGARAY, 2000, p.98).

Infelizmente ainda há a separação entre os conteúdos naturais e sociais no ensino de Geografia, mantendo-se, inclusive no livro didático, as "gavetinhas" dos conhecimentos geográficos. Por isso, o docente deve ter bem claro os conceitos da Geografia, uma vez que é necessário demonstrar domínio integrado sobre os conteúdos abordados em sala e possa cativar a atenção e aguçar o interesse dos alunos no desenvolvimento das práticas pedagógicas motivadoras e que envolvam os alunos na emoção da descoberta e no desejo de criação, como afirma Freire:

Que importa, na formação docente, não é a repetição mecânica do gesto, este ou aquele, mas a compreensão do valor dos sentimentos, das emoções, do desejo, da insegurança a ser superada pela segurança do medo que, ao ser educado, vai gerando a coragem. (1996, p.45).

Desta forma, o desenvolvimento das teorias e conceitos associado às atividades com experimentos pedagógicos permite melhor aprendizado dos assuntos apresentados e debatidos em aula, além de facilitar a compreensão dos conteúdos e relacionálos com o cotidiano do discente.

$\mathrm{O}$ ensino dos aspectos geográficos naturais, nesta linha metodológica, permite que o discente identifique no espaço geográfico as relações de tempo, entre a sociedade e a natureza. Analisar esse espaço com o auxílio de práticas pedagógicas permite que o aluno investigue de forma interativa as transformações dos espaços naturais e das paisagens, para entender a dinâmica socioambiental que o cerca.

Para ensinar Geografia Física partindo do abstrato para chegar ao concreto e vice-versa, devemos partir da explicação básica sobre as transformações físicas e ambientais do espaço, sendo a utilização de atividades experimentais um instrumento ideal para atingir esse objetivo, além da importância de se destacar o: 
Olhar geográfico, com base na teoria social, tem de trabalhar um método de análise que permita ver além das aparências, que consiga buscar as explicações para a compreensão dos fenômenos. Portanto, formar esse espírito geográfico requer o emprego de métodos de ensino que superem a simples transmissão de informações e que se assentem em alternativas para mobilizar o intelecto do aluno, fazendo com que ele se pergunte e não apenas espere respostas. (CALLAI, 1999, p.23).

Desse modo, torna-se necessário levar a teoria para sala de aula de forma concreta para que os alunos possam visualizar suas definições, além de perceberem a influência e importância desse conhecimento para as suas formações profissional e pessoal.

Porém, o que acaba sendo corriqueiro, nas escolas de Ensino Médio, é a presença de professores de Geografia que, ao ensinarem a área Física, enfrentam grandes dificuldades em construir o conhecimento juntamente com seus alunos de maneira satisfatória e agradável (contextualizada e funcional). Uma vez que a Geografia Física tem sido vista como uma tarefa difícil de ser compreendida, pelos alunos, e "repassada", pelos professores, levando assim à disciplina o desinteresse e dificuldades de aprendizagem dos conteúdos pelos alunos. Muitas vezes os professores não aprofundam ou excluem do plano de aula conceitos básicos e essenciais da Geografia Física para os alunos. Isso ocorre pelas deficiências na formação acadêmica e pelas dificuldades impostas pelas condições e rotina excessiva de trabalho. Contudo, o ato de experimentar no ensino de Geografia Física é de fundamental importância e emergencial.

É preciso romper a visão do ensino que é visto na atualidade, de um objeto abstrato, distante da realidade dos estudantes, o qual contribui para o desinteresse, na maioria das vezes, pelo trabalho escolar. Em que os discentes preocupam-se apenas com a nota e com a ascensão dos anos escolares, proporcionando que os conteúdos estudados sejam logo esquecidos e gerando com isso, o desinteresse nas aulas.

A transformação para uma consciência ambiental e sensibilidade intelectual diante dos problemas vivenciados tanto no meio de vivência como no mundo de forma global, só se consolidará por meio da associação entre teoria e prática. Os conteúdos referentes aos aspectos geográficos da natureza formam o substrato essencial à educação ambiental e as atividades práticas, os experimentos, formam os meios fundamentais à materialização desses conteúdos.

\subsection{A Importância dos Temas "Aquecimento Global" e "Bacias Hidrográficas" no Contexto Ambiental Atual}

A necessidade do estudo da temática ambiental está presente na vida da humanidade desde, principalmente, o advento do capitalismo, com a implantação de um sistema de produção em larga escala e com a apropriação da natureza enquanto mercadoria.

Porém, anterior a esse processo a Educação Ambiental em seus princípios básicos já existia, como é possível perceber nas palavras de Donella Meadows (1996, p. 21) "desde o primeiro momento em que os seres humanos começaram a interagir com o mundo ao seu redor, e ensinaram seus filhos a fazerem o mesmo, estava havendo educação e educação ambiental". Mas, com o início do processo de urbanização e industrialização a necessidade da educação ambiental se fez mais presente, pois o mundo começou a consolidar um modelo de "desenvolvimento ambientalmente insustentável" e a Educação Ambiental foi introduzida nas escolas por intermédio de disciplinas, como a Geografia e Biologia.

Até a primeira década dos anos 2000 os principais problemas ambientais possuíam dimensão local e regional e constituíam-se em despejo de resíduos químicos, industriais ou residenciais, in natura nos rios. $\mathrm{O}$ desmatamento das florestas e o êxodo rural que impulsionavam o crescimento populacional das cidades.

Hoje, os impactos ganharam repercussão em grande escala com o lançamento desenfreado de substâncias residuais provindos dos combustíveis fósseis, tendo a alteração da composição da atmosfera como maior impacto, resultando no processo de Aquecimento Global. Este, tornou-se o maior problema ambiental contemporâneo da humanidade que, a cada dia e com mais frequência, faz-se presente na pauta de discussões dos grupos científicos, de decisões econômicas, políticas, de saúde, saneamento e segurança alimentar, tornando-se, ainda, uma questão sociopolítica de imprescindível importância na atualidade.

Sendo também, um tema interdisciplinar relevante, é frequentemente abordado pelas mídias, além de estar atingindo grande parcela da opinião pública mundial e local. Estes meios de comunicação - jornal impresso, internet e telejornais - noticiam, frequentemente, as consequências dos desastres socioambientais causados em diversas partes do planeta e, dificilmente, as informações são acompanhadas de forma didática das explicações científicas emitidas pelo Painel Intergovernamental sobre Mudança Climática (IPCC).

As escolas podem (e devem) complementar a formação estudantil de jovens estudantes acerca de um problema de grande magnitude, como o aquecimento global. A associação de temática de caráter global com temas mais próximas à realidade do aluno como aqueles ligados às bacia hidrográficas, torna-se fecunda de possibilidades didáticas, incluindo atividades práticas que tornam mais "palpáveis" questões complexas. A partir desta perspectiva desenvolvemos o presente trabalho, que visa contribuir com a melhoria do processo de ensino-aprendizagem dos conteúdos de Geografia Física no Ensino Médio voltado à rede pública de ensino por meio de propostas de práticas experimentais.

Estabelecer processos de educação ambiental envolvendo a temática dos recursos hídricos com ênfase à bacia hidrográfica localizada no território onde se insere a escola, resgata a identidade dos discentes com o espaço vivido e os elementos ambientais contidos neste, levando o aluno a fazer as conexões entre os problemas ambientais locais e globais.

Por isso Porto (2008) acredita que é no espaço geográfico definido como território da bacia hidrográfica onde são desenvolvidas as atividades humanas e onde se repercutirá impactos significativos do aquecimento global. O espaço deste território seria constituído por

Todas as áreas urbanas, industriais, agrícolas ou de preservação fazem parte de alguma bacia hidrográfica... o que ali ocorre é consequência das formas de ocupação do 
território e da utilização das águas que para ali convergem (PORTO, 2008, p. 3).

Desse modo, a temática "bacia hidrográfica" constitui-se, em sua abordagem escolar, como ponte conectora, ao estabelecer uma articulação entre a educação ambiental e os conteúdos de Geografia Física do ensino médio. E, considerando-se o atual quadro de problemas, riscos e crise ambientais da sociedade contemporânea, diante do aquecimento global e das mudanças climáticas, este tema tem em sua importância o futuro do planeta.

Assim, deve-se considerar o tema como uma forma de abordar a sustentabilidade e proceder a educação ambiental no espaço escolar, além de despertar nos discente a importância das práticas socioambientais sustentáveis que busquem uma nova realidade e que possibilite mesclar a natureza com os avanços tecnológicos. (JACOBI, 2005, p. 243)

Neste contexto, é notório a importância do estudo destas questões para a formação intelectual e humana dos alunos do Ensino Médio. E com isso, levanta-se a pergunta sobre quais estratégias pedagógicas podem ser desenvolvidas pelos professores, em sala de aula, que leve a uma melhor compreensão das questões ambientais e suas relações globais e locais. A resposta abordada nesse trabalho refere-se à adoção de atividades experimentais com baixo custo e de fácil realização como via de materialização dos conceitos e processos científicos que envolvem as questões ambientais citadas.

2.4. As atividades experimentais como práticas de ensinoaprendizagem dos temas de Geografia Física no Ensino Médio

É necessário pensarmos na forma de abordagem da Geografia em sala de aula e se ela vai ou está influenciando na formação do discente, diante das mudanças constantes no espaço geográfico. Conforme PIRES (2012), a Geografia Escolar:

Após algumas décadas de um intenso e profundo movimento de renovação da Geografia brasileira (Nova Geografia, Geografia Crítica e Geografia Humanística), marcado, sobretudo, pela visão quantitativa, pelas teorias marxistas, pelas abordagens de cunho fenomenológico, hermenêutico e existencialista, as discussões teóricas e a aceitação de várias vertentes no campo de ensino da Geografia têm chegado às escolas de uma forma lenta e, em muitos contextos, ainda são pouco visíveis. (Pires, XVI ENDIPE, 2012).

Na maioria dos casos e muitas vezes pela falta de condições e recursos didáticos dados pela escola, há a utilização excessiva do livro didático, condicionando o ensino a ter caráter descritivo e excessivamente teórico, com poucas possibilidades de atividades práticas.

A Geografia Escolar finda por ser apresentada por meio de conteúdos descritivos, desarticulados, fragmentados e dissociados da realidade socioambiental vivida pelo aluno não

Permitindo que o aluno se aproprie dos conhecimentos geográficos de modo a compreendê-los, questioná-los e utilizá-los como instrumento do pensamento que extrapolam situações de ensino/aprendizagem eminentemente escolares, e colaborem para a formação de indivíduos críticos, conscientes e atuantes como cidadãos que refletem e interferem positivamente na sociedade contemporânea (PIRES, 2012, p.).

Pois quando a Geografia Escolar aborda o estudo dos aspectos físicos da paisagem é necessário,

Manter seu caráter crítico, socialmente engajado e comprometido, e que isso deve ser feito em consonância com a compreensão mais abrangente de que as sociedades estão sobre um mundo composto de elementos naturais. A dinâmica da natureza, sendo altamente suscetível aos impactos antrópicos, se reajusta rapidamente, provocando resultados nem sempre desejáveis para o homem. O conhecimento dos processos da natureza, o conhecimento do espaço produzido pelo homem e as condições necessárias à construção da cidadania ampliam a função do estudo do meio ambiente. (AFONSO e ARMOND, ENPEG, 2009)

Há inúmeras dificuldades encontradas pelos professores ao abordarem os conteúdos do livro de Geografia, sendo agravadas, em alguns casos, pela não formação específica na área que lecionam a disciplina, prejudicando assim o aprofundamento do ensinar geográfico e causando o não aprofundamento dos conteúdos, principalmente os referentes às paisagens naturais, e sem a sua correlação com o espaço vivido como apontam os PCN, pois sua compreensão e o entendimento da natureza e suas questões socioambientais são de grande importância para os alunos, uma vez que "permite ao professor trabalhar com uma grande diversidade de conteúdos da atualidade, interrelacionando os processos da natureza com as problemáticas colocadas para a sociedade do terceiro milênio" (BRASIL, 1998, p. 64).

No que se refere especificamente aos conteúdos de Climatologia do ensino médio da rede pública, o educador se depara com as dificuldades de recursos didáticos e de infraestrutura, além da complexidade dos conceitos abordados nos temas voltados aos sistemas naturais e como apresentar esses temas de forma dinâmica e que facilite a compreensão por parte dos alunos de temas como: "Aquecimento Global" e "Bacia Hidrográfica", levando em conta a importância das bacias hidrográficas para a sociedade e a sua influência na qualidade de vida, além das consequências do aquecimento global para a comunidade em geral, em seus vários aspectos (naturais, socioeconômicos, de saúde pública e etc.). Ou seja, o ensino desses temas de Geografia Física no Ensino Médio é, em geral, complexo para o professor que, em muitos casos, não está amparado com metodologias, recursos e práticas que facilitem a aprendizagem por parte do aluno que já vem de um Ensino Fundamental precário, com lacunas em relação aos conceitos básicos da Geografia.

Assim, emerge a necessidade de abordagens mais práticas, dinâmicas e interativas que estimulem o interesse dos alunos como a inclusão de experimentos simples e de baixo custo nas escolas, facilitando uma atitude mais ativa em relação às aulas, ajudando a romper com a passividade e excesso de abstração e descrição teórica de conteúdos. 
A atividade prática e a utilização de experimentos compõem uma indispensável estratégia no ensino de Geografia, principalmente nos estudos geográficos da natureza, e podem ser um recurso importante para o professor identificar as concepções prévias de seus alunos e colocá-las em confronto com as científicas.

Nesse aspecto, o docente assume o papel de mediador para conduzir um debate prévio entre os alunos, onde os mesmos exporão suas opiniões e depois confrontar com os resultados obtidos após as práticas. Por meio da observação e simulação do fenômeno natural/ambiental de forma mais ativa, os alunos podem assumir uma postura na busca de solução do problema e ainda perceber os mecanismos da dinâmica da natureza.

Como os fenômenos relacionados à natureza e às questões socioambientais são atributos elementares que fazem parte do aprendizado social e ecológico do aluno e a falta de recursos, por parte de muitas escolas privadas e da rede pública brasileira, é uma realidade, então, torna-se fundamental o desenvolvimento, dentro de sala de aula, de experimentos alternativos, em que o material utilizado seja de fácil montagem e aquisição tanto para os professores quanto para os alunos.

No presente trabalho serão abordadas atividades experimentais para facilitar o ensino-aprendizado da Geografia Física com foco nas áreas de Climatologia e Hidrogeografia, a partir dos temas "Aquecimento Global" e "Bacia Hidrográfica".

\subsection{As atividades experimentais}

A primeira e a segunda práticas sugeridas foram propostas originalmente pelos alunos de graduação do Curso de Licenciatura em Ciências da Natureza para o Ensino Fundamental, da Escola de Artes, Ciências e Humanidades da Universidade de São Paulo (USP) e se refere primeiramente ao tema "Aquecimento Global" (FARIAS, 2015) tendo o "Efeito Estufa" (Rankin, 2015) como exemplo da prática (objeto experimental) por ser o fenômeno considerado principal no processo que envolve o aquecimento climático. A partir dessas propostas fizemos adaptações que se adequassem à realidade das escolas públicas da região norte do Estado do Ceará.

Em aula antecedente, é importante que o professor trate os conteúdos das práticas, instigando a curiosidade e à pesquisa sobre os assuntos, inclusive, se possível exponha material audiovisual. No dia da aula prática, inicialmente, sugere-se que o professor comece a atividade, perguntando aos alunos o que eles sabem sobre o assunto para que haja maiores direcionamentos nas dúvidas e equívocos de suas concepções, após a contextualização, os alunos, preferencialmente em grupos, desenvolvem o experimento sob a orientação do professor.

2.5.1. Atividade Experimental I: Demonstração do mecanismo de funcionamento do efeito estufa e seus reflexos na temperatura da superfície terrestre.

$\mathrm{O}$ aquecimento global atual refere-se a aumento significativo da temperatura média da atmosfera da terra em um período relativamente muito curto e causado pela ação humana, principalmente pelo desmatamento e lançamento de resíduos dos combustíveis fósseis como o dióxido de carbono (CO2) e demais gases de efeito estufa (GEE) como o metano (CH4) e óxido nitroso (N2O).

Dessa forma o aquecimento global está ligado diretamente ao fenômeno chamado Efeito Estufa, que é provocado por alguns gases, em que os mais importantes são dióxido de carbono, óxido nitroso, metano e vapor de água, e que mesmo, sendo um fenômeno natural de aquecimento do planeta, tem sido agravado ao longo da história por causa da interferência humana na dinâmica do planeta.

O material necessário para a realização da atividade compreende: dois copos com água, papel alumínio, uma caixa de sapatos, uma tesoura e filme plástico.

A sua montagem inicia com a forragem do interior da caixa com o papel alumínio, depois coloca-se um dos copos com água dentro da caixa, e em seguida a caixa é tampada com o filme plástico (Figura 01).

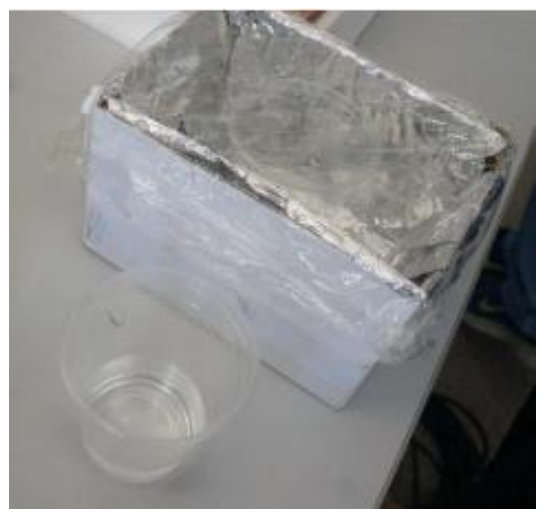

Figura 01: Demonstração dos Materiais Necessários Fonte: Arquivo Pessoal.

Para a realização da atividade é necessário colocar o segundo copo e a caixa sob a luz de uma lâmpada e após dez minutos abrir a caixa e perceber com o dedo qual dos dois copos está com a água mais quente (Figura 02).

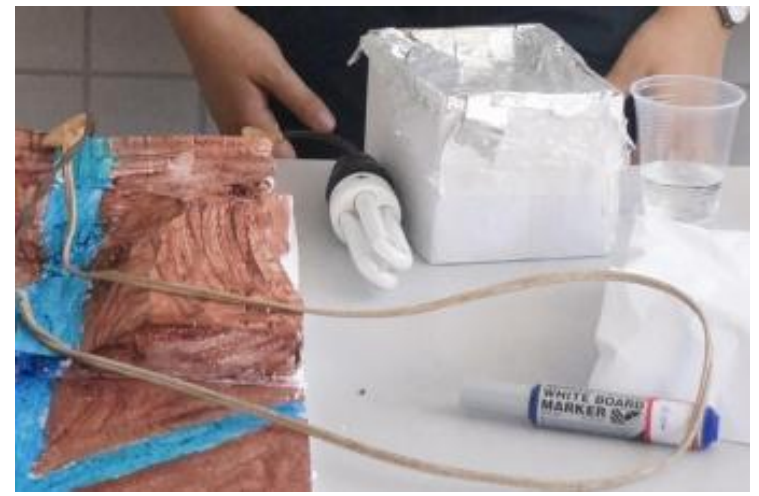

Figura 02: Demonstração do Efeito Estufa. Fonte: Arquivo Pessoal.

O experimento demonstra que ao iluminar a caixa (simulação da radiação solar), a luz passa pelo filme plástico e se transforma em calor ao atingir a superfície interna. $\mathrm{O}$ ar se aquece e como 
não pode sair da caixa, a temperatura interna da caixa aumenta. Por esse motivo, a temperatura da água do copo que está dentro da caixa, é maior do que a que está fora.

A partir desse experimento, pode-se refletir sobre as causas e as consequências do Efeito Estufa e tratar a questão do Aquecimento Global e a sua interferência na dinâmica planetária, principalmente as que envolvem a atmosfera, os oceanos e cobertura vegetal.

2.5.2. Atividade Experimental II: Demonstração em 3D do arranjo espacial de uma bacia hidrográfica.

Para essa atividade, a proposta é a construção de uma maquete (Figura 03) que pode ser muito utilizada em aulas de Geomorfologia ou Higrogeografia, a partir de mapas com curvas de nível que podem ter seus detalhes topográficos construídos, com certa facilidade, promovendo a visualização em 3D do arranjo espacial de uma bacia hidrográfica $(\mathrm{BH})$, onde as nascentes, rio principal, afluentes, áreas de interflúvio e seus segmentos de alto, médio e baixo cursos serão observados de forma integrada.

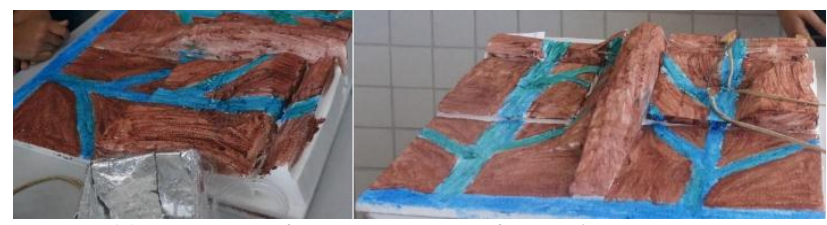

Figura 03: Maquete de uma Bacia Hidrográfica. Fonte: Arquivo pessoal

O procedimento para o desenvolvimento dessa atividade inicia com o desenho em folha fina do contorno geral da área da $\mathrm{BH}$; posteriormente, desenhar, no mesmo tipo de folha, toda curva de nível de menor altitude; em seguida, desenhar em folhas separadas, cada uma das curvas de nível mapeadas e colar cada uma dessas folhas sobre isopor de meio centímetro, recortar o isopor seguindo as curvas do papel sobre ele colada, usando agulha quente; por fim, colar as peças (as curvas de nível recortadas), umas sobre as outras, seguindo a ordem das curvas de nível, montando assim o relevo da área da $\mathrm{BH}$ : as curvas de maior altitude sobre as de menor, até o topo do segmento mais alto do relevo e finalizar com a pintura (indica-se tinta à base de água).

Esta maquete de $\mathrm{BH}$, em especial, promove a identificação das linhas divisoras de água e outras de importância para o estudo do relevo e pontos de cume, além da visualização do curso da água e representação de bacia hidrográfica

\section{CONS IDERAÇÕES FINAIS}

As atividades experimentais compõem estratégias fundamentais na superação das dificuldades encontradas no processo de ensino-aprendizagem de conceitos científicos geográficos, não somente por propiciar interpretações, discussões e confrontos de ideias entre os estudantes, mas pela natureza investigativa, interativa e prática.

Diante da complexidade das temáticas/fenômenos relacionados a vários conteúdos da Geografia Física escolar, como Aquecimento Global e Bacias Hidrográficas, e da necessidade técnica e metodológica de apoio didático além do livro didático, verifica-se que a utilização de atividades experimentais como forma de incentivar alunos e professores ao conhecimento científico dos fenômenos naturais é uma via eficaz e fecunda, principalmente em se tratando de escolas da rede pública que possuem maior deficiência em recursos didáticos, pois pode-se materiais acessíveis usados no dia-a-dia.

As atividades experimentais podem e devem se tornar práticas pedagógicas mais presentes nas estratégicas de ensinoaprendizagem, visto o salto no desenvolvimento cognitivo do aluno que elas proporcionam e suas possibilidades de aplicação em sala. Além de seu papel pedagógico, os experimentos também se transformam em momentos em que se desenvolve a interação e a socialização, e potencializa a criatividade dos alunos.

Os resultados podem ser ampliados quando as atividades experimentais propostas pelo professor promovem relação com a realidade do aluno, fazendo o diálogo entre suas vivências e os conteúdos materializados na prática experimental. Assim como, por meio do desenvolvimento de experimentos propostos pelos próprios alunos, a partir de ideias originais de materialização de seus conhecimentos aprendidos.

\section{REFERÊNCIAS}

AFONSO, Anice Esteves; ARMOND. Núbia Beray. Reflexões sobre o ensino de geografia física no ensino fundamental e médio: breve histórico da cisão e da reaproximação. $10^{\circ}$ ENCONTRO NACIONAL DE PRATICAS DE ENSINO DE GEOGRAFIA-ENPEG, 2009, Porto Alegre.

AUSUBEL, D. P.; NOVAK, J. D.; HANESIAN, H. Educational Psychology: A Cognitive view. Nova York: Holt, Rinehardt \& Winston, 1978.

BIZZO, N. Ciências: fácil ou difícil? São Paulo: Ática, 2000.

BORDENAVE, J. D.; PEREIRA, A. M. O papel dos meios multissensoriais no ensino aprendizagem. In: Estratégias de Ensino Aprendizagem. 22. ed. Petrópolis: Vozes, 2001. p.203-219.

BORGES, A. T. Novos rumos para o laboratório escolar de ciências. Caderno Brasileiro de Ensino de Física, v.19, p.291-313, dez. 2002.

BRASIL. MEC - Ministério da Educação. Parâmetros Curriculares Nacionais para o Ensino Médio: Geografia, 1998 / geografia / Secretaria de Educação Fundamental. Brasília: MEC/ SEF, 1998.. Disponível em: http://portal.mec.gov.br/seb/arquivos/pdf/cienciah.pdf. Acesso em: 30 jun. 2018.

CALLAI, Helena. A formação do profissional da geografia. Ijuí: Editora UNIJUİ, 1999.

CAMPOS, E. O contexto espacial e o currículo de geografia no ensino médio: um estudo em ilha bela. (Mestrado) Faculdade de Educação da USP, São Paulo, 2005. 
CARVALHO, A. M. P. Critérios Estruturantes para o Ensino de das Ciências. In: CARVAlHO, A. M. P de (Org.). Ensino de Ciências: Unindo Pesquisa e Prática. São Paulo: Pioneira Thomson Learning, 2006.

CARVALHO, Marline Conceição Vieira de. As Práticas pedagógicas na sala de aula e a qualidade do Processo Ensino-Aprendizagem - Estudo de caso: escola secundária de Achada Grande. Universidade Jean Piaget de Cabo Verde. Cidade da Praia, Santiago - Cabo Verde. 2009.

DIAS, Genebaldo Freire. Educação Ambiental: princípios e práticas. São Paulo: Editora Gaia, 2000.

FARIAS, Ivone Dantas. Simulador do Efeito Estufa. Ciência à Mão. Universidade de São Paulo - USP. 2006/2015. Disponível em: http://www.cienciamao.usp.br/tudo/exibir.php?midia=lcn\& cod=_geocienciassimuladordoef. Acesso em: 13 de maio de 2018.

FREIRE, Paulo. Pedagogia do Oprimido. 17. ed. Rio de Janeiro: Editora: Paz e Terra, 1987. Pedagogia da autonomia: saberes necessários à prática educativa. 36 . ed. São Paulo: Paz e Terra, 1996.

GALIAZZI, Maria do Carmo et al. Objetivos das atividades experimentais no ensino médio: a pesquisa coletiva como modo de formação de professores de ciências. Ciência \& Educação, n. 7, v. 2, p. 249-263, 2001.

GÓMEZ, Angel I. Pérez. Qualidade do ensino e desenvolvimento profissional do docente como intelectual reflexivo. $\mathrm{V}$ SIMPÓSIO PAULISTA DE EDUCAÇÃO FÍSICA. Motriz, v. 3, n.1, 1997.

HELLER, A. $O$ cotidiano e a história. 4.ed. São Paulo: Paz e Terra, 1992.

JACOBI, P. Meio Ambiente e Sustentabilidade. In: CEPAM Município do Século XXI. São Paulo, 1999, p.180.

KRASILCHIK, Myriam. Prática de Ensino de Biologia. São Paulo: Edusp, 2008.

LUNETTA, V. N. Atividades práticas no ensino da Ciência. Revista Portuguesa de Educação, v.2, p. 81-90, 1991.

MEADOWS, Donella H. Harvesting one Hundredfold - Key concepts and CaseStudies. In: Environmental Education, United Nations Environment Programme UNEP/UNESCO, 1989.

PIRES, Lucineide Mendes. Ensino de Geografia: Cotidiano, Práticas e Saberes. XVI ENDIPE - Encontro Nacional de Didática e Práticas de Ensino - UNICAMP - Campinas. 2012.

PORTO, M. F. do A; PORTO \& PORTO, R. L. L. Gestão de Bacias Hidrográficas. In: Estudos Avançados, v. 22, n. 63. São Paulo, 2008.
Rankin, André Stopa. Simulação: Derretimento das Geleiras do Artico e da Antartida. Ciência à Mão. Universidade de São Paulo - USP. 2006/2015. Disponível em: http ://www.cienciamao.usp.br/tudo/exibir.php ?midia=lcn\& cod=_simulacaododerretimentod. Acesso em: 13 de maio de 2018.

SUERTEGARAY, D. M. A. O que ensinar em Geografia (Física)? In: REGO, N. SUERTEGARAY, D. M. A.; HEIDRICH, A. (Org). Geografia e Educação: Geração de Ambiências. Porto Alegre: Ed. Universidade/UFRGS, 2000.

Recebido em: 13/09/2019

Aceito para publicação em: 29/12/2019 